\title{
OPERATION ANALYSIS OF SOFT SWITCHING PWM DC-DC CONVERTER WITH SECONDARY SNUBBER
}

The paper deals with analysis of operation of a soft switching PWM DC-DC full-bridge converter with new energy recovery turn-off snubber on secondary side of high frequency power transformer.

Principal equations are derived for individual operation states. On the basis of them the diagrams are made out. The diagrams give complex image on the converter behaviour during whole period of operation at nominal load. Theoretical waveforms are compared with simulation results.

Keywords: Snubber, soft switching, zero voltage zero current switching, PWM, DC-DC converter.

\section{Introduction}

DC-DC converter is the main and most important part of voltage or current switching power supplies. Full bridge pulse-width modulated (PWM) DC-DC converters have been often used in high power high frequency applications because they have several advantages over resonant converters [1]-[17]. Diode output rectifier is mostly employed on the secondary side of the power transformer to rectify high frequency secondary voltage [1]-[8]. Various snubbers, clamps and auxiliary circuits are often added on secondary side to ensure soft switching of the main switches and suppression of converter circulating currents [4]-[10]. The features of these configurations are quite well known and widely described in many papers. Very effective way, how to decrease circulating currents in the converter and simultaneously achieve reduction of switching losses, is to utilize a controlled output rectifier [18]-[21]. According to control algorithm it is either zero-voltage or zero current turn off achieved at inverter transistors. The ZVZCS PWM DC-DC converter with secondary controlled rectifier, novel turn-off energy recovery snubber and new method of control is shown in Fig. 1.

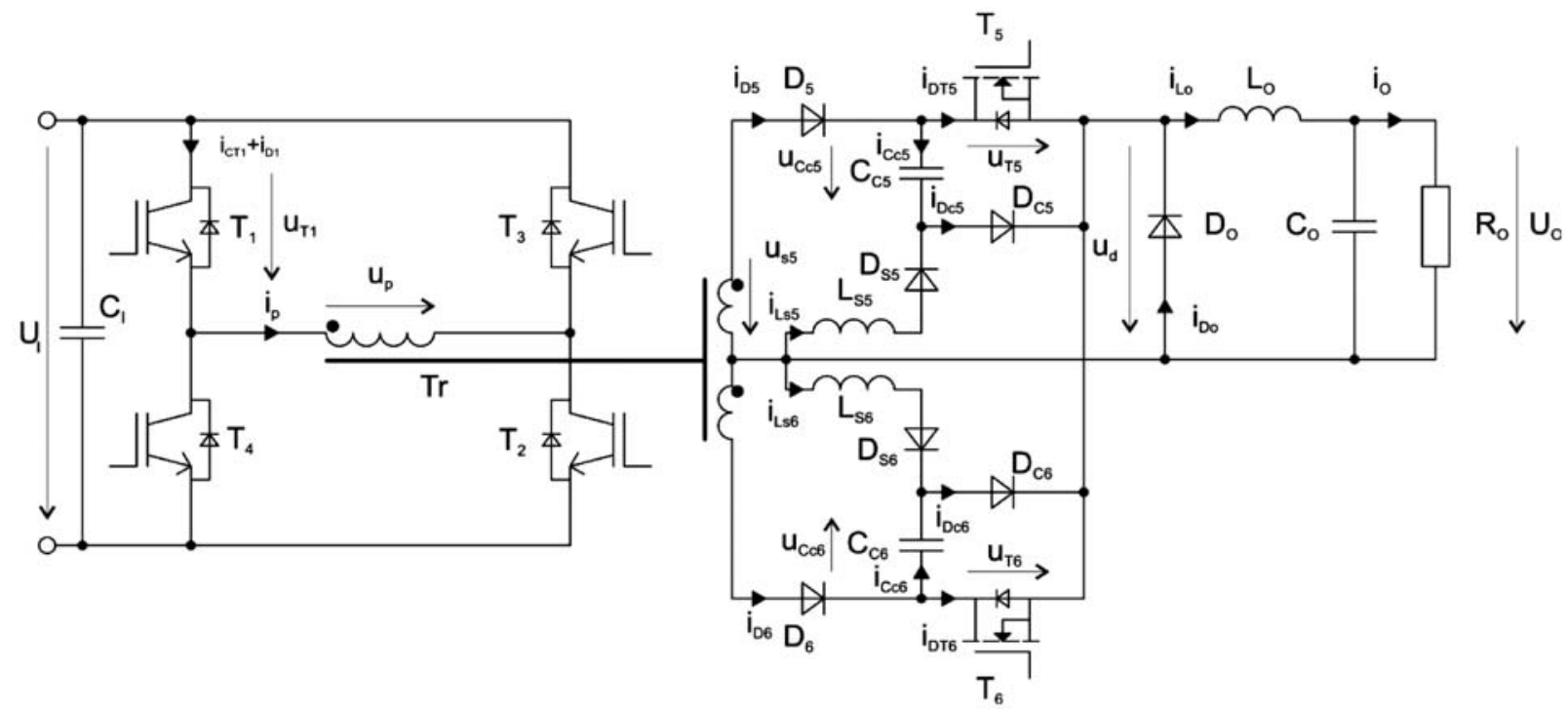

Fig. 1 Scheme of the proposed converter

\footnotetext{
* Dudrik Jaroslav ${ }^{1}$, Bodor Marcel $^{2}$, Trip Nistor Daniel ${ }^{3}$

${ }^{1}$ Technical University of Kosice, Kosice, Slovakia, E-mail: jaroslav.dudrik@tuke.sk

${ }^{2}$ Johnson Controls Innotec Technologies, Lucenec, Slovakia

${ }^{3}$ University of Oradea, Oradea, Romania
} 
The proposed converter in Fig. 1 consists of high frequency full-bridge inverter $\left(T_{1}-T_{4}\right)$, high frequency centre tapped power transformer $\mathrm{T}_{\mathrm{r}}$, controlled output rectifier $\left(\mathrm{T}_{5}, \mathrm{D}_{5} ; \mathrm{T}_{6}, \mathrm{D}_{6}\right)$, freewheeling diode $\mathrm{D}_{\mathrm{O}}$, output filter $\left(\mathrm{L}_{\mathrm{O}}, \mathrm{C}_{\mathrm{O}}\right)$ and novel type of secondary turn-off snubber $\left(\mathrm{C}_{\mathrm{C} 5}, \mathrm{C}_{\mathrm{C} 6}, \mathrm{~L}_{\mathrm{S} 5}, \mathrm{~L}_{\mathrm{S} 6}, \mathrm{D}_{\mathrm{S} 5}, \mathrm{D}_{\mathrm{S} 6}, \mathrm{D}_{\mathrm{C} 5}, \mathrm{D}_{\mathrm{C} 6}\right)$.

The converter is controlled by new algorithm of pulse-width modulation (Fig. 2). The secondary switches are turned-off earlier than primary switches and thus zero-voltage turn-on and zero-current turn-off all of the transistors $T_{1}-T_{4}$ in the inverter are reached.

The new snubber circuit eliminates the turn off losses of the secondary transistors. The semiconductor switches $\mathrm{T}_{5}, \mathrm{~T}_{6}$ in the secondary side are used to reset secondary and simultaneously also primary circulating current. The energy stored in the leakage inductance of the power transformer is transferred to the load.

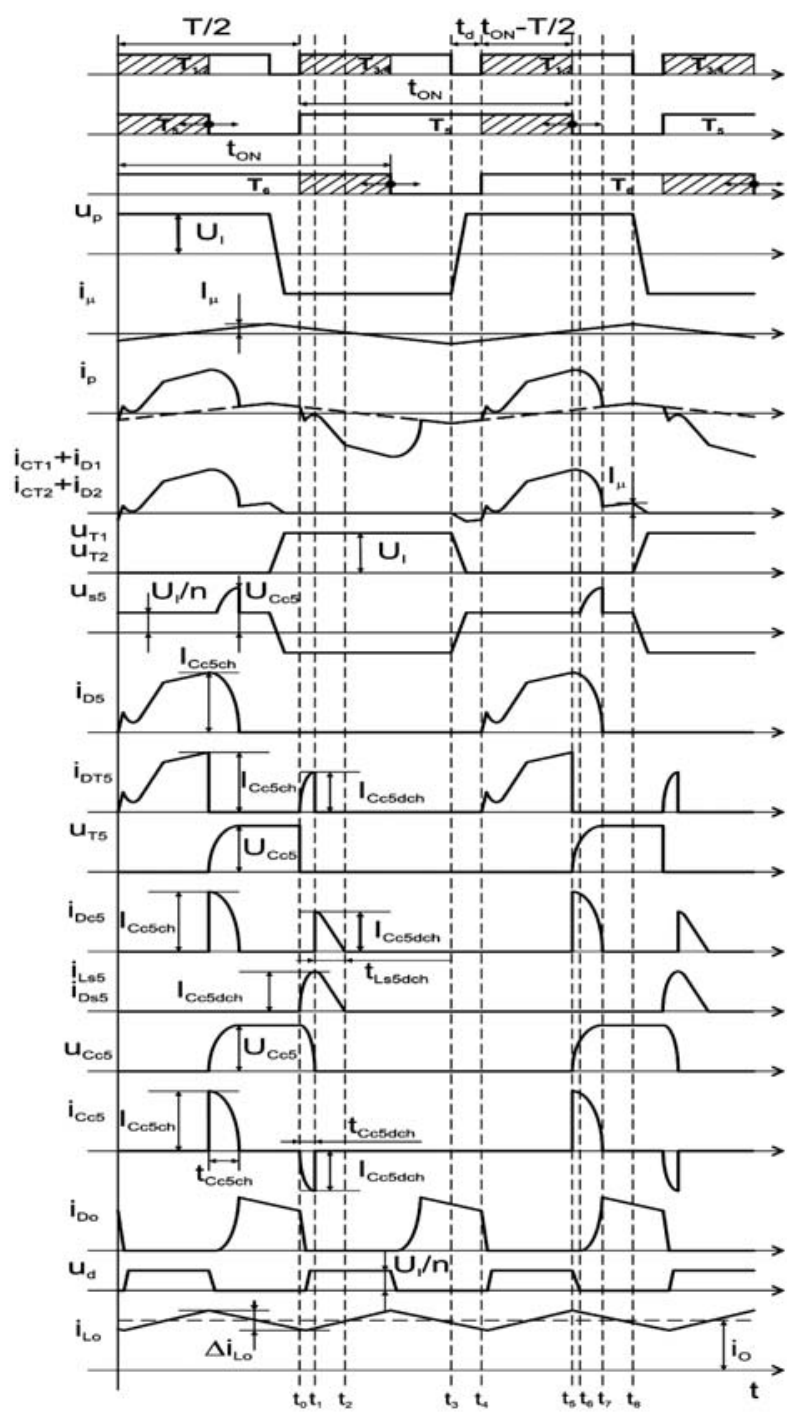

Fig. 2 Operation waveforms

\section{Converter operation}

The switching diagram and operation waveforms are shown in Fig. 2. DC/DC converter is controlled by novel modified pulse width modulation with variable phase shift between primary and secondary switches. The transient time analysis is done in distinctive intervals with help of Laplace-Carson transform. It is assumed that all components and devices are ideal.

Interval $\left(\mathbf{t}_{0}-\mathbf{t}_{1}\right)$ :

Operation of the converter in interval $t_{0}-t_{1}$ is shown in Fig. 3. The secondary transistor $T_{5}$ is turned on at $t_{0}$ half period earlier than primary transistors $T_{1}$ and $T_{2}$. The capacitor $C_{C 5}$ starts discharging through $\mathrm{T}_{5}, \mathrm{~L}_{\mathrm{O}}, \mathrm{R}_{\mathrm{O}}, \mathrm{L}_{\mathrm{S}}$, and $\mathrm{D}_{\mathrm{S} 5}$. The rate of rise of discharging current of this capacitor $\mathrm{C}_{\mathrm{C}}$ is limited by the snubber circuit inductance $\mathrm{L}_{\mathrm{S} 5}$, and thus zero current turn on for the MOSFET transistor $T_{5}$ is achieved. In the same time transistors $T_{3}$, $\mathrm{T}_{4}$ are turned on. Because the transistor $\mathrm{T}_{6}$ is already in on-state, so the output voltage of the rectifier $u_{p}$ is equalled $U_{I} / n$ (where $n=u_{p} / u_{s}$ is transformer turn's ratio). The current of the primary transistors $\mathrm{T}_{3}, \mathrm{~T}_{4}$ and the current of the secondary transistor $\mathrm{T}_{6}$ are reduced by the discharging current of capacitor $\mathrm{C}_{\mathrm{C} 5}$.

For mathematical analysis the equivalent operator circuit in each interval of converter operation was created as it is present in Fig. 4 for interval $t_{0}-t_{1}$.
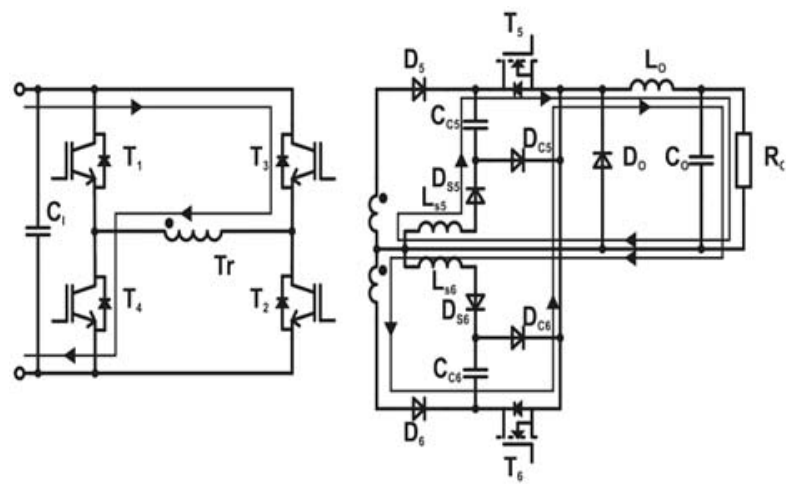

Fig. 3 Operation of the converter in interval $t_{0}-t_{I}$

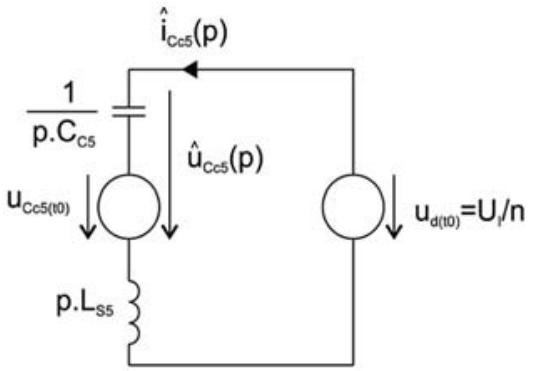

Fig. 4 Equivalent operator circuit for interval $t_{0}-t_{l}$ 
Capacitor $C_{C 5}$ voltage and current image can be found from operator scheme in Fig. 4 as follows

$$
\begin{aligned}
& \hat{i}_{C c 5}(p)=\frac{u_{d\left(t_{0}\right)}-u_{C c 5\left(t_{0}\right)}}{\frac{1}{p C_{C 5}}+p L_{S 5}} \\
& \hat{u}_{C c 5}(p)=\hat{i}_{C c 5}(p) \frac{1}{p C_{C 5}}+u_{C c 5\left(t_{0}\right)}
\end{aligned}
$$

Initial conditions are

$$
\begin{aligned}
& u_{d\left(t_{0}\right)}=\frac{U_{I}}{n} \\
& u_{C c 5\left(t_{0}\right)}=U_{C c 5}
\end{aligned}
$$

Voltage and current time waveforms are

$$
\begin{aligned}
& i_{C c 5}(t)=\sqrt{\frac{C_{C 5}}{L_{S 5}}}\left(\frac{U_{I}}{n}-U_{C c 5}\right) \sin \left(\frac{t-t_{0}}{\sqrt{L_{S 5} C_{C 5}}}\right) \\
& u_{c c 5}(t)=\frac{U_{I}}{n}+\left(U_{C c 5}-\frac{U_{I}}{n}\right) \cos \left(\frac{t-t_{0}}{\sqrt{L_{S 5} C_{C 5}}}\right)
\end{aligned}
$$

From equation (6) follows that total discharging of the capacitor occurs only in the case if its initial voltage $U_{C c 5}$ is higher than double rectified voltage $u_{d}=U_{I} / n$

$$
\frac{U_{I}}{n}+\left(U_{c c 5}-\frac{U_{I}}{n}\right)(-1) \leq 0 \rightarrow U_{c c 5} \geq 2 \frac{U_{I}}{n}
$$

If condition (7) is valid, capacitor discharging time (when $\left.u_{C c 5}(t)=0\right)$ can be obtained from equation (6)

$$
c c s d c h=t_{1}-t_{0}=\sqrt{L_{S 5} C_{C 5}} \arccos \left(\frac{\frac{U_{I}}{n}}{\frac{U_{I}}{n}-U_{C c 5}}\right)
$$

Discharging time is from interval

$$
\frac{\pi}{2} \sqrt{L_{S 5} C_{C 5}}<t_{C c 5 d c h} \leq \pi \sqrt{L_{S 5} C_{C 5}}
$$

As discharging time is greater than quarter of resonance period, the magnitude of the discharging current of the capacitor can be calculated from equation (5)

$$
I_{C c 5 d c h}=\left|\sqrt{\frac{C_{C 5}}{L_{S 5}}}\left(\frac{U_{I}}{n}-U_{C c 5}\right)\right|=\sqrt{\frac{C_{C 5}}{L_{S 5}}}\left(U_{c c 5}-\frac{U_{I}}{n}\right)
$$

Interval $\left(t_{1}-t_{2}\right)$ :

The energy stored in snubber inductance $\mathrm{L}_{\mathrm{S}}$ is now flowing through $\mathrm{D}_{\mathrm{S} 5}, \mathrm{D}_{\mathrm{C} 5}, \mathrm{~L}_{\mathrm{O}}, \mathrm{R}_{\mathrm{O}}, \mathrm{L}_{\mathrm{S}}$. At $\mathrm{t}_{2}$ the whole load current flows through the transistor $\mathrm{T}_{6}$ as it is seen in Fig. 5. The indispensable equations for this interval can be derived from equivalent operator circuit shown in Fig. 6.

The snubber inductor current decays to zero according to

$$
i_{L s 5}(t)=\sqrt{U_{C c 5}\left(U_{C c 5}-2 \frac{U_{I}}{n}\right)} \sqrt{\frac{C_{C 5}}{L_{S 5}}}-\frac{U_{I}}{n} \frac{t-t_{1}}{L_{S 5}}
$$

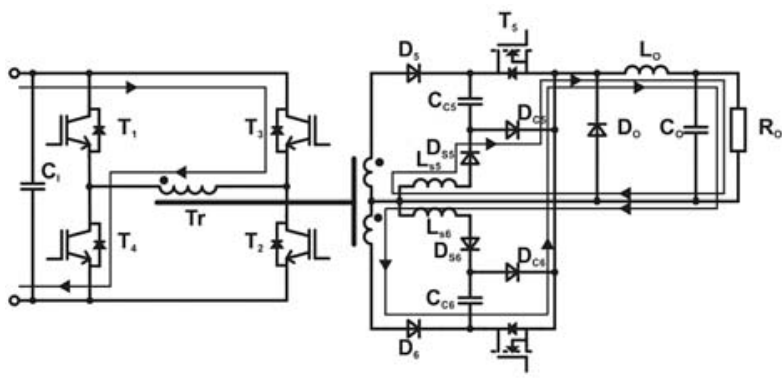

Fig. 5 Operation of the converter in interval $t_{1}-t_{2}$

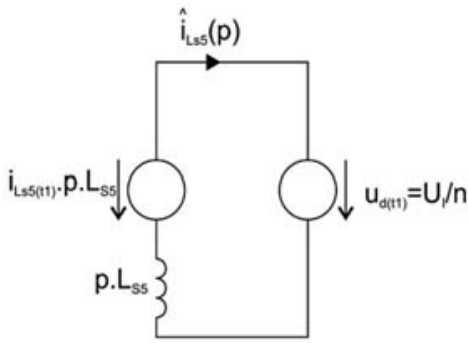

Fig. 6 Equivalent operator circuit for interval $t_{1}-t_{2}$

From this equation decay time of the inductor current can be determined

$$
t_{L s 5 d c h}=t_{2}-t_{1} \frac{\sqrt{U_{C c 5}\left(U_{C c 5}-2 \frac{U_{I}}{n}\right)} \sqrt{\frac{C_{C 5}}{L_{S 5}}}}{\frac{U_{I}}{n}} L_{S 5}
$$

Interval $\left(t_{3}-t_{4}\right)$ :

This interval starts with the turn off of the primary transistors $T_{3}$ and $T_{4}$. The magnetizing current of the transformer $T_{r}$ discharges the output capacitances $\mathrm{C}_{\text {OSS }}$ of the transistors $\mathrm{T}_{1}, \mathrm{~T}_{2}$ and charges the output capacitances of the transistors $\mathrm{T}_{3}, \mathrm{~T}_{4}$ (Fig. 7).

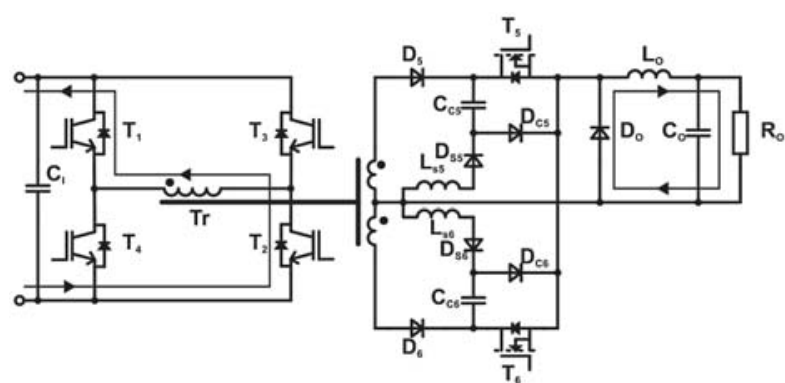

Fig. 7 Operation of the converter in interval $t_{3}-t_{4}$

If we assume that magnetizing inductance of power transformer and output smoothing inductance are much smaller than leakage inductances $\left(\mathrm{L}_{1 \mathrm{H}}, \mathrm{L}_{\mathrm{O}}<<\mathrm{L}_{1 \sigma}, \mathrm{L}^{\prime}{ }_{2 \sigma}\right)$, then simplified equations for 


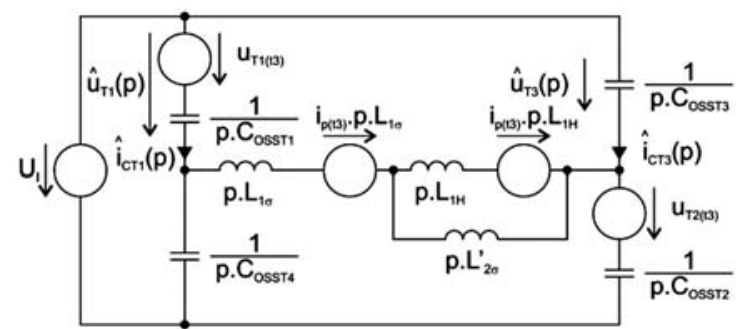

Fig. 8 Equivalent operator circuit for interval $t_{3}-t_{4}$

collector-emitter voltages of the primary transistors $T_{1}, T_{2}$, and $\mathrm{T}_{3}, \mathrm{~T}_{4}$ are obtained from Fig. 8 as follows

$$
\begin{aligned}
& u_{T 1}(t)=u_{T 2}(t)=\frac{1}{2} U_{I}\left(1+\cos \left(\sqrt{\frac{1}{C_{\text {OSS }}}}\left(t-t_{3}\right)\right)\right)- \\
& -\frac{1}{2} I_{\mu} \sqrt{\frac{L_{\sigma}}{C_{\text {OSS }}}} \sin \left(\sqrt{\frac{1}{C_{\text {OSS }} L_{\sigma}}}\left(t-t_{3}\right)\right) \\
& u_{T 3}(t)=u_{T 4}(t)=\frac{1}{2} U_{I}\left(1-\cos \left(\sqrt{\frac{1}{C_{\text {OSS }} L_{\sigma}}}\left(t-t_{3}\right)\right)\right)+ \\
& +\frac{1}{2} I_{\mu} \sqrt{\frac{L_{\sigma}}{C_{\text {OSS }}}} \sin \left(\sqrt{\frac{1}{C_{\text {OSS }} L_{\sigma}}}\left(t-t_{3}\right)\right)
\end{aligned}
$$

Where $L_{\sigma}=L_{1 \sigma}+L_{2 \sigma}^{\prime}$

The minimum (transistors $\mathrm{T}_{1}, \mathrm{~T}_{2}$ ) or maximum (transistors $\mathrm{T}_{3}$, $\mathrm{T}_{4}$ ) collector-emitter voltages are achieved during following interval

$$
t_{4}-t_{3}=t_{d} \approx \pi \sqrt{C_{\text {osS }}\left(L_{1 \sigma}+L_{2 \sigma}^{\prime}\right)}
$$

Interval $\left(t_{4}-t_{5}\right)$ :

The turn on of the transistors $T_{1}, T_{2}$ and $T_{6}$ commutation from freewheeling diode to $T_{5}$ transistor occur at $t_{4}$ (Fig. 2). The current of transistor $\mathrm{T}_{5}$ is reduced by the discharge current of the capacitor $\mathrm{C}_{\mathrm{C} 6}$ and later by the current of the inductance $\mathrm{L}_{\mathrm{S} 6}$ (Fig. 9).

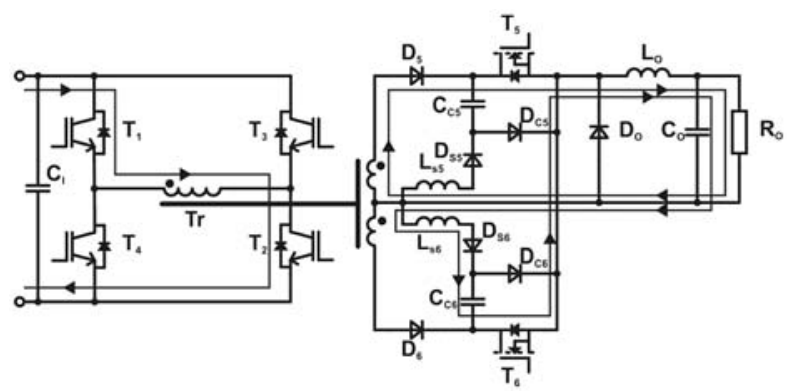

Fig. 9 Operation of the converter in interval $t_{4}-t_{5}$

Rate of rise of collector current of the secondary transistor $\mathrm{T}_{5}$
Rate of rise of collector current of the primary transistors $T_{1}$, $\mathrm{T}_{2}$ is a little higher

$$
\frac{d i_{C T 1, C T 2}}{d t}=\frac{U_{I}}{\left(L_{1 H}+L_{1 \sigma}\right)}+\frac{U_{I}}{\left(L_{1 \sigma}+L_{2 \sigma}^{\prime}\right)}
$$

\section{Interval $\left(t_{5}-t_{6}\right)$ :}

At $t_{5}$ transistor $T_{5}$ turns off. Its current commutates on capacitor $\mathrm{C}_{\mathrm{C} 5}$ and diode $\mathrm{D}_{\mathrm{C} 5}$ and consequently zero voltage turn off of this transistor is ensured. The energy of the leakage inductance of the power transformer is absorbed by the snubber capacitance and then transferred to the load. The situation is displayed in Fig. 10 .

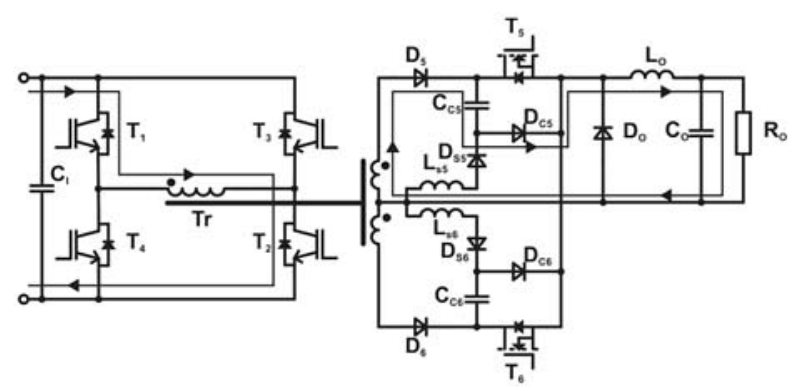

Fig. 10 Operation of the converter in interval $t_{5}-t_{6}$

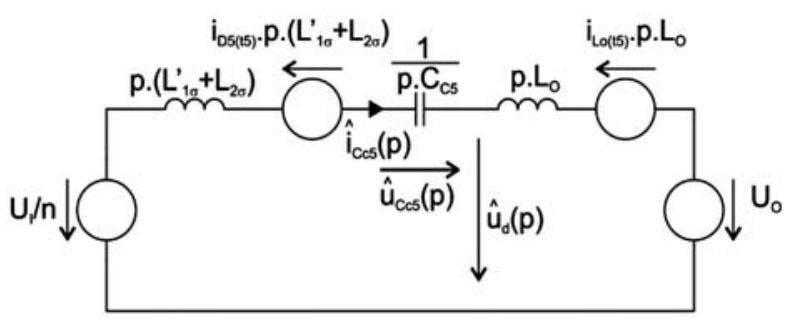

Fig. 11 Equivalent operator circuit for interval $t_{5}-t_{6}$

When assuming that Lo $>>\mathrm{L}^{\prime}{ }_{1 \sigma}, \mathrm{L}_{2 \sigma}$, then capacitor current and capacitor voltage are described by the next simplified equations according to Fig. 11

$$
\begin{aligned}
& i_{C c 5}(t) \approx I_{C c 5 c h} \cos \left(\frac{t-t_{5}}{\sqrt{C_{C 5} L_{O}}}\right)+ \\
& +\left(\frac{U_{I}}{n}-U_{O}\right) \sqrt{\frac{C_{C 5}}{L_{O}}} \sin \left(\frac{t-t_{5}}{\sqrt{C_{C 5} L_{O}}}\right) \\
& u_{C c 5}(t) \approx I_{C c 5 c h} \sqrt{\frac{L_{O}}{C_{C 5}}} \sin \left(\frac{t-t_{5}}{\sqrt{C_{C 5} L_{O}}}\right)+ \\
& +\left(U_{O}-\frac{U_{I}}{n}\right) \cos \left(\frac{t-t_{5}}{\sqrt{C_{C 5} L_{O}}}\right)+\frac{U_{I}}{n}-U_{O}
\end{aligned}
$$


The rectified secondary voltage drops to zero according to equation

$$
\begin{aligned}
& u_{d}(t) \approx U_{O}\left(\frac{U_{I}}{n}-U_{O}\right) \cos \left(\frac{t-t_{5}}{\sqrt{C_{C 5} L_{O}}}\right)- \\
& -I_{C c 5 c h} \sqrt{\frac{L_{O}}{C_{C 5}}} \sin \left(\frac{t-t_{5}}{\sqrt{C_{C 5} L_{O}}}\right)
\end{aligned}
$$

The time needed to decreasing the rectified voltage to zero during this interval can be calculated from (20) and it is approximately

$$
t_{6}-t_{5} \approx \sqrt{C_{C 5} L_{O}} \arcsin \left(\frac{U_{O}}{I_{C c 5 c h}} \sqrt{\frac{C_{C 5}}{L_{O}}}\right)
$$

Interval $\left(\mathbf{t}_{\mathbf{6}}-\mathbf{t}_{7}\right)$ :

Operation of the converter in this interval is shown in Fig. 12. At $t_{6}$ (Fig. 2) the rectified voltage ud reached zero and afterwards the waveform of the charging process of the $\mathrm{C}_{\mathrm{C} 5}$ capacitance are changed. In this interval the whole energy of the leakage inductance is absorbed by the capacitor $\mathrm{C}_{\mathrm{C} 5}$.

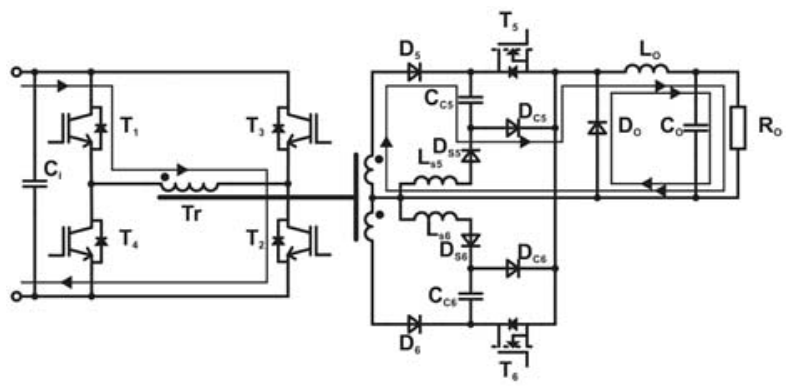

Fig. 12 Operation of the converter in interval $t_{6}-t_{7}$

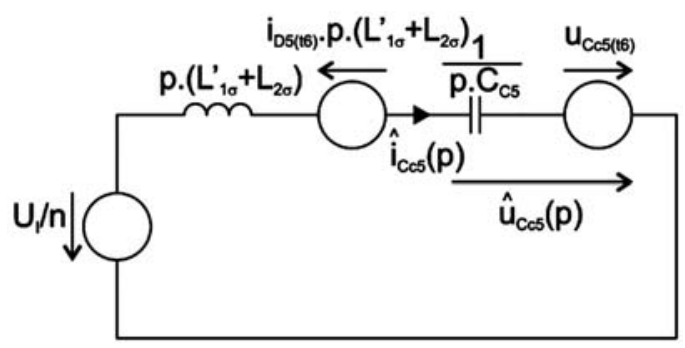

Fig. 13 Equivalent operator circuit for interval $t_{6}-t_{7}$

At $t_{7}$ the current of the rectifier diode $\mathrm{D}_{5}$ falls to zero, and the primary current that flows through the transistor $T_{1}$ and $T_{2}$ drops on value of the magnetizing current. 13 as

Charging current of the capacitor can be expressed from Fig.

$$
\begin{aligned}
& i_{C c 5}(t)=i_{C c 5\left(t_{6}\right)} \cos \left(\frac{t-t_{6}}{\sqrt{C_{C 5} L_{\sigma}^{\prime}}}\right)+ \\
& +\left(\frac{U_{I}}{n}-u_{C c 5\left(t_{\sigma}\right)}\right) \sqrt{\frac{C_{C 5}}{L_{\sigma}^{\prime}}} \sin \left(\frac{t-t_{6}}{\sqrt{C_{C 5} L_{\sigma}^{\prime}}}\right)
\end{aligned}
$$

where $L_{\sigma}^{\prime}=L_{1 \sigma}^{\prime}+L_{2 \sigma}^{\prime}$

The capacitor voltage rises according to equation

$$
\begin{aligned}
& u_{C c 5}(t)=\frac{U_{I}}{n}+\left(u_{C c 5\left(t_{\sigma}\right)}-\frac{U_{I}}{n}\right) \cos \left(\frac{t-t_{6}}{\sqrt{C_{C 5} L_{\sigma}^{\prime}}}\right)+ \\
& +i_{C c 5\left(t_{t}\right)} \sqrt{\frac{L_{\sigma}^{\prime}}{C_{C 5}}} \sin \left(\frac{t-t_{6}}{\sqrt{C_{C 5} L_{\sigma}^{\prime}}}\right)
\end{aligned}
$$

In $\mathrm{t}_{7}$ the current flowing through rectifying diode $\mathrm{D}_{5}$ decays to zero and current of the transistors $T_{1}, T_{2}$ drops to value of magnetizing current of the transformer, because capacitor absorbed all the leakage inductance energy. This time interval is expressed by

$$
t_{7}-t_{6}=\sqrt{C_{C 5} L_{\sigma}^{\prime}} \arctan \left(\frac{i_{C c 5\left(t_{\sigma}\right)}}{\sqrt{\frac{C_{C 5}}{L_{\sigma}^{\prime}}}\left(u_{C c 5\left(t_{6}\right)}-\frac{U_{I}}{n}\right)}\right)
$$

Where $u_{C c 5\left(t_{o}\right)} \approx \frac{U_{I}}{n}$ and $i_{C c 5\left(t_{o}\right)} \approx I_{C c s c h}=i_{o}+\frac{\Delta i_{L o}}{2}$

Charging time of the capacitor is approximately sum of equations (21) and (24)

$$
t_{C c 5 c h}=t_{7}-t_{5} \approx \frac{\pi}{2} \sqrt{C_{C 5}\left(L_{1 \sigma}^{\prime}+L_{2 \sigma}\right)}
$$

Voltage of the capacitor after charging is

$$
U_{C c 5} \approx \frac{U_{I}}{n}+\left(i_{o}+\frac{\Delta i_{L o}}{2}\right) \sqrt{\frac{\left(L_{1 \sigma}^{\prime}+L_{2 \sigma}\right)}{C_{C 5}}}
$$

Interval $\left(t_{7}-t_{8}\right)$ :

Only the magnetizing current flows through the primary winding of the power transformer in this interval (Fig. 14). This small magnetizing current is turned off by primary switches and thus zero current turn off is achieved. The current of the smoothing inductance $\mathrm{L}_{\mathrm{O}}$ is flowing through the freewheeling diode.

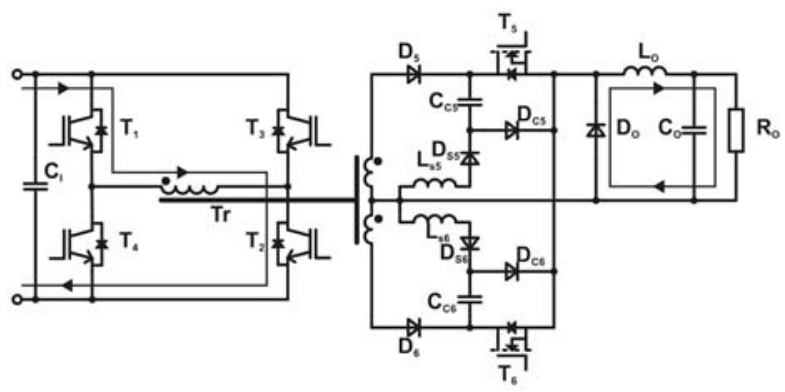

Fig. 14 Operation of the converter in interval $t_{7}-t_{8}$ 
At $\mathrm{t}_{8}$ the primary transistors turn-off only magnetizing current, whose magnitude is given by

$$
I_{\mu}=\frac{U_{I}}{2\left(L_{1 H}+L_{1 \sigma}\right)} \frac{T}{2}
$$

The smoothing inductance current ripple is

$\Delta i_{L o}=\frac{U_{o}}{L_{O}} \frac{T}{2}(1-d)$

Where $d=\frac{\left(t_{O N}-\frac{T}{2}\right)}{\frac{T}{2}}$ is duty cycle

Output voltage can be determined as

$U_{o}=\frac{\left(t_{O N}-\frac{T}{2}\right)}{\frac{T}{2}} \frac{U_{I}}{n}=d \frac{U_{I}}{n}$

Then smoothing inductance current ripple can be expressed as

$$
\Delta i_{L o}=\frac{T}{2 L_{o}}\left(U_{o}-\frac{U_{o}^{2}}{U_{I}} n\right)=\frac{U_{I} T}{2 n L_{o}}\left(d-d^{2}\right)
$$

The output voltage ripple is given by

$$
\begin{aligned}
& \Delta U_{o}=\frac{1}{C_{O}} \int_{0}^{d \frac{T}{2}} \frac{\Delta i_{L o}}{d \frac{T}{2}} t d t= \\
& =\frac{T^{2}}{8 C_{O} L_{O}}\left(\frac{U_{O}^{2}}{U_{I}} n-\frac{U_{O}^{3}}{U_{I}^{2}} n^{2}\right)=\frac{U_{I} T^{2}}{8 n C_{O} L_{O}}\left(d^{2}-d^{3}\right)
\end{aligned}
$$

\section{Simulation results}

The theoretical analysis was verified by simulation of the proposed converter in program OrCad. The results confirm zero voltage turn-on and zero current turn-off of primary switches (Fig. 15) and zero current turn-on and zero voltage turn-off of the secondary switches (Fig. 16).

The secondary turn-off snubber works also in compliance with theoretical assumptions as it is shown in Fig. 17. The circulating current is totally depressed as can be seen in Fig. 18, where the primary current decays to value of magnetizing current of the transformer.

\section{Conclusion}

Detail mathematical description of the proposed converter allows understanding individual dependences and gives the complex view on converter behaviour. On the basis of this analysis it is possible to make optimization of the converter devices from the point of their own operation as well as the converter operation. The

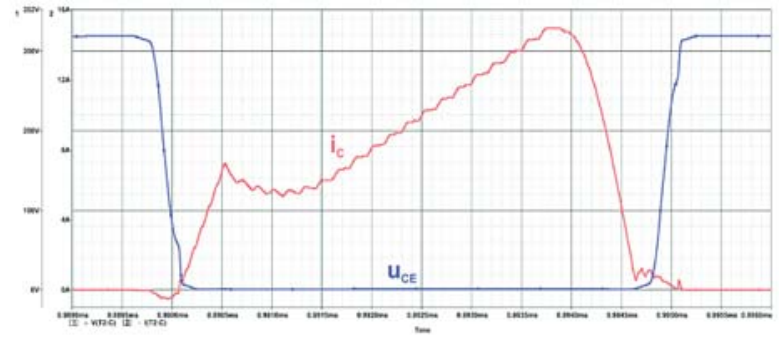

Fig. 15 Collector current $i_{C}$ and collector-emitter voltage $u_{C E}$ of the inverter transistor $T_{2}$ at turn-on and turn-off

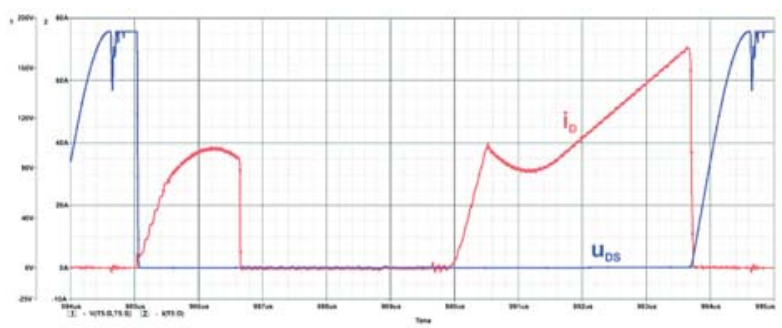

Fig. 16 Collector current $i_{D}$ and collector-emitter voltage $u_{D S}$ of the output rectifier transistor $T_{5}$ at turn-on and turn-off

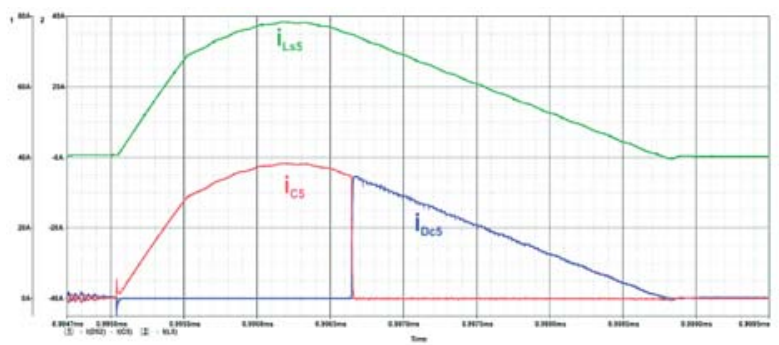

Fig. 17 Current of the snubber inductor $L_{S 5}$, capacitor $C_{C 5}$ and diode $D_{C 5}$

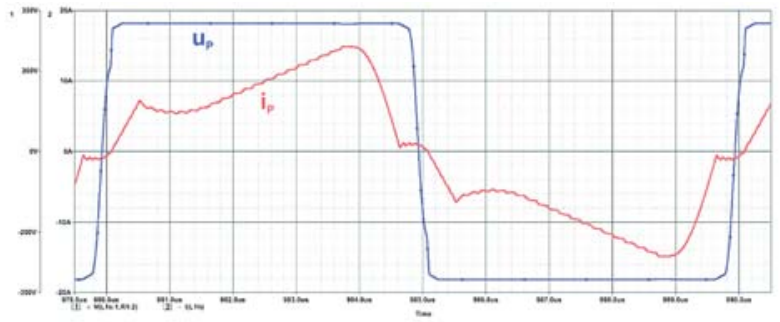

Fig. 18 Primary voltage $u_{P}$ and current $i_{P}$ of the power transformer

present analysis can also help at calculation and optimization of the converter efficiency. By using the new secondary energy recovery turn-off snubber and used control algorithm the turn-off losses of the primary switches are considerably reduced. Moreover, the circulating current is suppressed by controlled rectifier and thus efficiency of the converter is increased. 


\section{Acknowledgement}

This work was supported by the Slovak Research and Development Agency under the contract No. APVV-0185-10 and R\&D operational program Centre of excellence of power electronics systems and materials for their components No. OPVaV2008/2.1/01-SORO, ITMS 26220120003 funded by European regional development fund (ERDF).

\section{References}

[1] CHOI, H. S., KIM, J. W., CHO, B. H.: Novel Zero-voltage and Zero-current-switching (ZVZCS) Full-bridge PWM Converter Using Coupled Output Inductor, IEEE Transactions on Power Electronics, vol. 17, No. 5, 2002, pp. 641-648.

[2] JEON, S. J. , CHO, G. H.: A Zero-Voltage and Zero Current Switching Full Bridge DC-DC Converter With Transformer Isolation, IEEE Trans. on Power Electronics, vol.16, No. 5, 2001, pp. 573-580.

[3] BOJOI, R., GRIVA, G., KOVACEVIC, G., TENCONI, A.: ZVS-ZCS Full-Bridge DC-DC Converter for Voltage Step-up in Fuel Cell Distributed Generation Systems, Record, European Conference on Power Electronics and Applications, 2-5 Sept. 2007, pp. 1-8.

[4] MOISSEEV, S. SATO, S. HAMADA, S., NAKAOKA, M.: Full Bridge Soft-Switching Phase-Shift PWM DC-DC Converter Using Tapped Inductor Filter, Record, PESC 2003, pp. 1826-1831.

[5] DUDRIK, J.: High Frequency Soft Switching DC-DC Power Converters (in Slovak), Monograph, Elfa: Kosice, Slovakia, 2007.

[6] CHLEBIS, P.: Soft Switching Converters (in Czech), Monograph, VSB-TU Ostrava, Ostrava, 2004, ISBN 80-248-0643-6, 148 p.

[7] TEREN, A., FENO, I., SPANIK. P.: DC/DC Converters with Soft (ZVS) Switching, Record, Elektro 2001, section - Electrical Engineering, Zilina, 2001, pp. 82-90.

[8] DUDRIK, J., SPANIK, P., TRIP, D. N.: Zero Voltage and Zero Current Switching Full-Bridge DC-DC Converter with Auxiliary Transformer, IEEE Trans. on Power Electronics, vol. 21, No. 5, 2006, pp. 1328-1335.

[9] LIU, R.: Comparative Study of Snubber Circuits for DC-DC Converters Utilized in High Power Off-line Power Supply Applications, Record, IEEE APEC'99, pp. 821-826.

[10] HIMMELSTOSS, F. A., VOTZI, H. L.: Combined Forward-Flyback-Converter with Only Two Diodes - Function And Modelling, Communications - Scientific Letters of the University of Zilina, No. 2a, 2011, pp. 6-12.

[11] SPANIK, P. KANDRAC, J., FRIVALDSKY, M., DRGONA, P.: Verification of Operation Modes of Designed LLC Resonant Converter, Communications - Scientific Letters of the University of Zilina, No. 2a, 2011, pp. 67-3.

[12] HAMAR, J., NAGY, I., STUMPF, P., OHSAKI, H,. MASADA, E.: New Dual Channel Quasi Resonant DC-DC Converter Topologies for Distributed Energy Utilization, Record, EPE -PEMC 2008, pp.1778-1785.

[13] PETROV, S.: Expectations of Resonant Converters Utilization as Welding Power Sources, Schematics No. 7, 2006, pp. 30-33 (in Russian).

[14] HAMAR, J., BUTI, B., NAGY. I.: Dual Channel Resonant DC-DC Converter Family, EPE J., vol. 17, No. 3, 2007, pp. 5-15.

[15] DOBRUCKY, B., BENOVA, M. FRIVALDSKY, M. PRAZENICA, M.: Choosing Modulation Strategies for 2-Stage Combine LLC- and Direct Converter-Modelling, Simulation, Application, Communications Scientific Letters of the University of Zilina, No. 2a, 2011, pp. 25-31.

[16] PAVLOVSKY, M., DE HAAN, S. W. H., FERREIRA, J. A.: Reaching High Power Density in Multikilowatt DC-DC Converters with Galvanic Isolation, IEEE Transactions on Power Electronics, vol. 24, No. 3-4, 2009, pp. 603-612.

[17] PAUL, A. K., SINGH, S., CHINOY, S.: Quality Engineering Aspects of Series Resonant Induction Heating Power Supply with Wide Coil Range, PCIM Europe, Nurnberg, 2008, pp. 173-178.

[18] HARADA, K., ISHARA, Y., TODAKA, T.: Analysis and Design of ZVS-PWM Half-Bridge Converter with Secondary Switches, Record, IEEE power Electronics Specialists Conference, PESC 95, vol. 1, June, 1995, pp. 280-285.

[19] DUDRIK, J., TRIP, D. N.: Soft-Switching PS-PWM DC-DC Converter for Full-Load Range Applications, IEEE Transactions on Industrial Electronics, vol. 57, No. 8, 2010, pp. 2807-2814.

[20] DUDRIK, J.: Soft Switching Full-Bridge PWM DC/DC Converter Using Secondary Snubber, in: Journal of Electrical and Electronics Engineering, vol. 2, No. 1, 2009, pp. 147-150.

[21] DUDRIK, J., RUSCIN, V., BODOR, M.: Soft Switching DC/DC Converter Using Controlled Output Rectifier with Secondary Turnoff Snubber, EDPE 2009: Abstracts \& CD Proc. of 15th Intern. Conference on Electrical Drives and Power Electronics : 4th Joint Croatia-Slovakia Conference, October, 2009, Dubrovnik: Zagreb, KoREMA, 2009, pp. 1-5. 